\title{
Effects of dietary fat on fertility of dairy cattle: A meta-analysis and meta-regression
}

\author{
R. M. Rodney, ${ }^{+} \dagger^{1}$ P. Celi, $\dagger$ W. Scott, ${ }^{*}$ K. Breinhild, ${ }^{*}$ and I. J. Lean* \\ *SBScibus, Camden, New South Wales, Australia 2570 \\ †Dairy Science Group, Faculty of Veterinary Science, The University of Sydney, Camden, New South Wales, Australia 2570
}

\begin{abstract}
Evidence is increasing of positive effects of feeding fats during transition on fertility and the adaptation to lactation. This study used meta-analytic methods to explore the effects of including fats in the transition diet on the risk of pregnancy to service (proportion pregnant) and calving to pregnancy interval. Meta-analysis was used to integrate smaller studies and increase the statistical power over that of any single study and explore new hypotheses. We explored the effect of fats and diet composition on fertility using meta-regression methods. Relatively few highly controlled studies are available providing detailed descriptions of the diets used that examined interactions between fat nutrition and reproductive outcomes. Only 17 studies containing 26 comparisons were suitable for inclusion in statistical evaluations. Reproductive variables evaluated were risk of pregnancy (proportion pregnant), primarily to first service, and calving to pregnancy interval. Production variables examined were milk yield, milk composition, and body weight. The sources of heterogeneity in these studies were also explored. A $27 \%$ overall increase in pregnancy to service was observed (relative risk $=1.27$; 95\% confidence interval Knapp Hartung 1.09 to 1.45), and results were relatively consistent $\left(I^{2}=19.9 \%\right)$. A strong indication of a reduction in calving to pregnancy interval was also identified, which was consistent across studies $\left(I^{2}=0.0 \%\right)$, supporting a conclusion that, overall, the inclusion of fats does improve fertility. Further exploration of the factors contributing to proportion pregnant using bivariate meta-regression identified variables that reflected changes in diet composition or animal response resulting from inclusion of the fat interventions in the experimental diets fed. Increased fermentable neutral detergent fiber and soluble fiber
\end{abstract}

Received March 3, 2015.

Accepted April 28, 2015.

${ }^{1}$ Corresponding author: rachaelr@sbscibus.com.au intakes increased the proportion pregnant, whereas increased milk yield of the treatment group decreased this measure. Unexpectedly, the estimated energy costs of urea production also had a positive association with proportion pregnant. The limited number of suitable studies for the analysis highlights the need for more work to improve understanding of the critical nutritional factors affecting fertility. These factors include specific fatty acids in dietary interventions that contribute to increasing fertility of cows in dairy production systems. Key words: dietary fat, fertility, conjugated linoleic acid

\section{INTRODUCTION}

Managing fertility of lactating dairy cattle is a challenge for dairy producers because poor fertility reduces productivity and profit. Declines in fertility have been noted and reflect associations with intensification of production and higher levels of milk production (Butler, 2000; Lucy, 2001; Lean et al., 2008; Thatcher et al., 2011). Studies are needed to identify which environmental factors, especially nutritional ones, may have a role in influencing the fertility of cattle.

The transition period, from approximately 3 wk before to $3 \mathrm{wk}$ after calving, is characterized by changes in metabolism as dairy cattle respond to the metabolic challenges of late pregnancy and early lactation (Bell, 1995). Good management during the transition period, in particular nutritional strategies, can reduce the effects of this metabolic stress and improve production and reproduction (De Veth et al., 2009). DeGaris et al. $(2010 \mathrm{a}, \mathrm{b})$ found that the risk of pregnancy increased by approximately $30 \%$ in cattle exposed to transition diets for $20 \mathrm{~d}$ compared with cattle not exposed.

Recent understandings of the role of fats in metabolism open new opportunities for improving production, health, and reproduction in cattle. Inclusion of fats in the diet during this transition period has improved reproductive performance (Thatcher et al., 2006; De Veth et al., 2009), improved energy balance (von Soosten et 
al., 2012), reduced the incidence of metabolic diseases, and allowed energy density to be maintained in diets without increasing the use of rapidly fermentable carbohydrates.

The strength of meta-analytic methods is the ability to integrate smaller studies using effect-size metrics, enhance the statistical power over that of any single study, and provide the potential to explore new hypotheses (Lean et al., 2009). Further, the challenge in studies of nutrition and reproduction is that when a nutritional intervention is applied, something else in the diet necessarily changes (Lean et al., 2012). Therefore, the potential for confounding influences need to be considered in interpreting studies of nutrition and reproduction. Meta-regression methods allow this type of investigation. This study was designed to use metaanalytic and meta-regression methods to explore the effects of including fats in the diet during the transition period on measures of pregnancy, calving to pregnancy interval, and milk yield and components, and the factors that may explain sources of variation in these responses.

\section{MATERIALS AND METHODS}

\section{Literature Search}

A systematic review, across 3 databases (PubMed, Web of Science CABI, and Google Scholar) and references in papers, was used to identify studies exploring fat nutrition during transition and fertility that were published in English between 1970 and 2014 in a peer-reviewed journal, conference proceedings, or as an accepted thesis. Combinations of the following search terms were used: cow, cattle, dairy, fertility, pregnancy, reproduction, pregnancy, fat, CLA, conjugated linoleic acid, cottonseed, linoleic acid, linolenic acid, omega-6, omega-3, and energy.

\section{Inclusion and Exclusion Criteria}

Papers were deemed suitable for inclusion in the study if they were randomized controlled experiments using Bos taurus dairy cows in their first or later lactation during the dry/lactating period (i.e., primiparous nonlactating heifers were excluded). Studies evaluated the effect of feeding during the transition period, including the period 3 wk before and after calving, and included sufficient dietary details for the diet to be evaluated using CPM-Dairy (version 3.08; CornellPenn-Miner, http://cahpwww.vet.upenn.edu/doku.php /software:cpm:purchase) for cows that were fed as individuals or in appropriately replicated pens. Papers that had valid interventions, but did not provide adequate dietary detail, or animals were group fed and not replicated, were identified, but diets were not extracted. Measures of fertility were reported as (1) first service conception or pregnancy to a defined number of services (proportion pregnant); (2) calving to pregnancy interval; or both (1) and (2); and a measure of dispersion suitable to provide a standard deviation. Studies were also assessed for quality of study design including details of randomization, appropriate analysis, and elimination of bias or confounding. The number of cows in each treatment and control group and measures of variance or $P$-values for continuous variables that allowed an estimate of standard deviation to be derived must have been reported.

\section{Data and Diet Extraction}

Data extracted included authors, year, journal and type of publication, title of paper, feeding system, number of cows in treatment and control groups, parity, BW, and BCS for each group. Reproductive variables that were recorded were defined as proportion of cows pregnant to service [reported in the papers as first service pregnancy percentage or conception rate, pregnancy percentage (rate) to first 2 services, or pregnancy] and calving to pregnancy intervals (also reported as calving to conception interval or days open) for each treatment. Milk production $(\mathrm{kg} / \mathrm{cow}$ per $\mathrm{d})$, milk fat percentage and yield $(\mathrm{kg} / \mathrm{cow}$ per $\mathrm{d})$, and milk protein percentage and yield $(\mathrm{kg} / \mathrm{cow}$ per $\mathrm{d})$ were also recorded. Data were extracted and entered into a spreadsheet (Excel, Microsoft Corp., Redmond, WA). A summary of studies included is provided in Table 1.

To extract and model dietary information, data from accepted papers were entered into CPM-Dairy (version 3.08; Cornell-Penn-Miner, http://cahpwww. vet.upenn.edu/doku.php/software:cpm:purchase) following the standard operating procedure described in Rabiee et al. (2012). Ration ingredients and intake in the papers were entered into CPM-Dairy using ingredients selected from the feed bank (http://cahpwww. vet.upenn.edu/doku.php/software:cpm:fbk_use) and edited to the specifications described in the paper. This was combined with information on cows, housing, and environment from the paper to predict diet composition. If uncertainty was present with regard to the unit of interest or measures of dispersion reported in papers, authors were contacted to provide clarification of these measures.

\section{Statistical Analysis}

All statistical analyses were conducted using Stata (Intercooled Stata v.13, Statacorp, College Station, 
TX). The influence of fat nutrition during transition on production and reproductive performance was analyzed using meta-analysis. Trials were grouped by type of fat intervention [oilseeds, calcium salts of FA (CSFA), tallow, CLA, or other], and meta-analyses were conducted for each group and overall. Meta-analyses were conducted to examine the effects of fat intervention on risk of pregnancy to service (proportion pregnant to service), primarily reported to first service; days from calving to pregnancy; and milk yield and composition (milk protein yield, milk protein percentage, milk fat yield, and milk fat percentage). Further meta-analyses, of reproductive variables only, were conducted that also included data from the papers identified as having valid intervention but lacking adequate detail. Dichotomous data were analyzed by using relative risk (RR) and continuous data by standardized mean difference (SMD), which is also called effect size analysis. The RR estimates were pooled using methods for random effects models to evaluate the effect of trial, with the Hartung-Knapp-Sidik-Jonkman (Knapp-Hartung) method (IntHout et al., 2014). The use of this method for meta-analysis is more robust than alternative methods such as the DerSimonian and Laird method for discrete data, especially where heterogeneity is present (IntHout et al., 2014). As described by IntHout et al. (2014), the DerSimonian and Laird method uses the normal distribution to derive $P$-values and confidence intervals, whereas the Knapp-Hartung method uses the $t$-distribution with $k-1$ degrees of freedom, where $k$ is the number of studies in the meta-analysis. IntHout et al. (2014) describes the estimated variance of $\hat{y}_{\tau}$ using the DerSimonian and Laird method as

$$
\operatorname{var}_{\mathrm{DL}}=\frac{1}{\sum w_{i}^{\tau}},
$$

whereas the Knapp-Hartung method estimated the variance as

$$
\operatorname{var}_{\mathrm{KH}}=\frac{\sum w_{i}^{\tau}\left(y_{i}-\hat{y}_{\tau}\right)^{2}}{(k-1) \sum w_{i}^{\tau}},
$$

where $k$ is the number of studies, $y_{i}$ is the effect size estimate from the $i$ th study, $w_{i}$ is the fixed effect weight, and $\tau^{2}$ is the heterogeneity of the effect size between studies. If the paper reported separate estimates of measures of variance (SE or SD) for each group, these were recorded as such. Many studies reported a common SE or SD, and these estimates were used for both control and treatment groups. Where SE was reported, a SD was derived before analysis. Some studies reported exact $P$-values, which were used to estimate SD.

Random effects models (DerSimonian and Laird, 1986) were used to evaluate production outcomes (milk yield, milk protein yield, milk protein percentage, milk fat yield, and milk fat percentage) and BW, estimating the SMD, 95\% confidence intervals, and statistical significance of SMD. Where only one comparison was available in a group, that group was not reported individually and was only included in the overall pooled result. The approximate predictive interval (Harris et al., 2008) for the treatment effect was also explored, but because this was very large in some cases, reflecting small numbers of studies in some groups, it was not included in forest plots. We recognize the presence of a clustering effect that results from multiple comparisons to a single control group within a study. We have determined that the variance inflation effect resulting from high intra-class correlations from clustering will be minor unless very large numbers of repeated comparisons are present. The statistical methods for the meta-analytic procedures that were used in this paper have been based on those published by one of the authors of this study (Lean et al., 2009).

\section{Forest Plots}

The effects of treatments on proportion pregnant to service, calving to pregnancy interval, and milk yield are displayed in the forest plots, using the estimated $\mathrm{RR}$ or SMD. The weighting of a study is estimated by the inverse of the variance of the effect size. Boxes draw attention to the studies with the greatest weight.

\section{Assessment of Heterogeneity}

Variations among the trial level RR or SMD were assessed using a $\chi^{2}(\mathrm{Q})$ test of heterogeneity. Heterogeneity in studies reflects underlying differences in clinical diversity of the herds and treatments used, differences in study design and analytical methods, and statistical variation around responses. Identifying the presence and sources of the heterogeneity improves understanding of the responses to treatments. We used an $\alpha$ level of 0.10 because of the relatively poor power of the $\chi^{2}$ test to detect heterogeneity among small numbers of trials. Heterogeneity of results among the trials was quantified using the $I^{2}$ statistic (Higgins and Thompson, 2002), who developed this measure of the effect of heterogeneity on a meta-analysis, from mathematical criteria, that are independent of the number of studies and the treatment effect metric. The $I^{2}$ statistic is a transformation of the square root of the $\chi^{2}$ heteroge- 


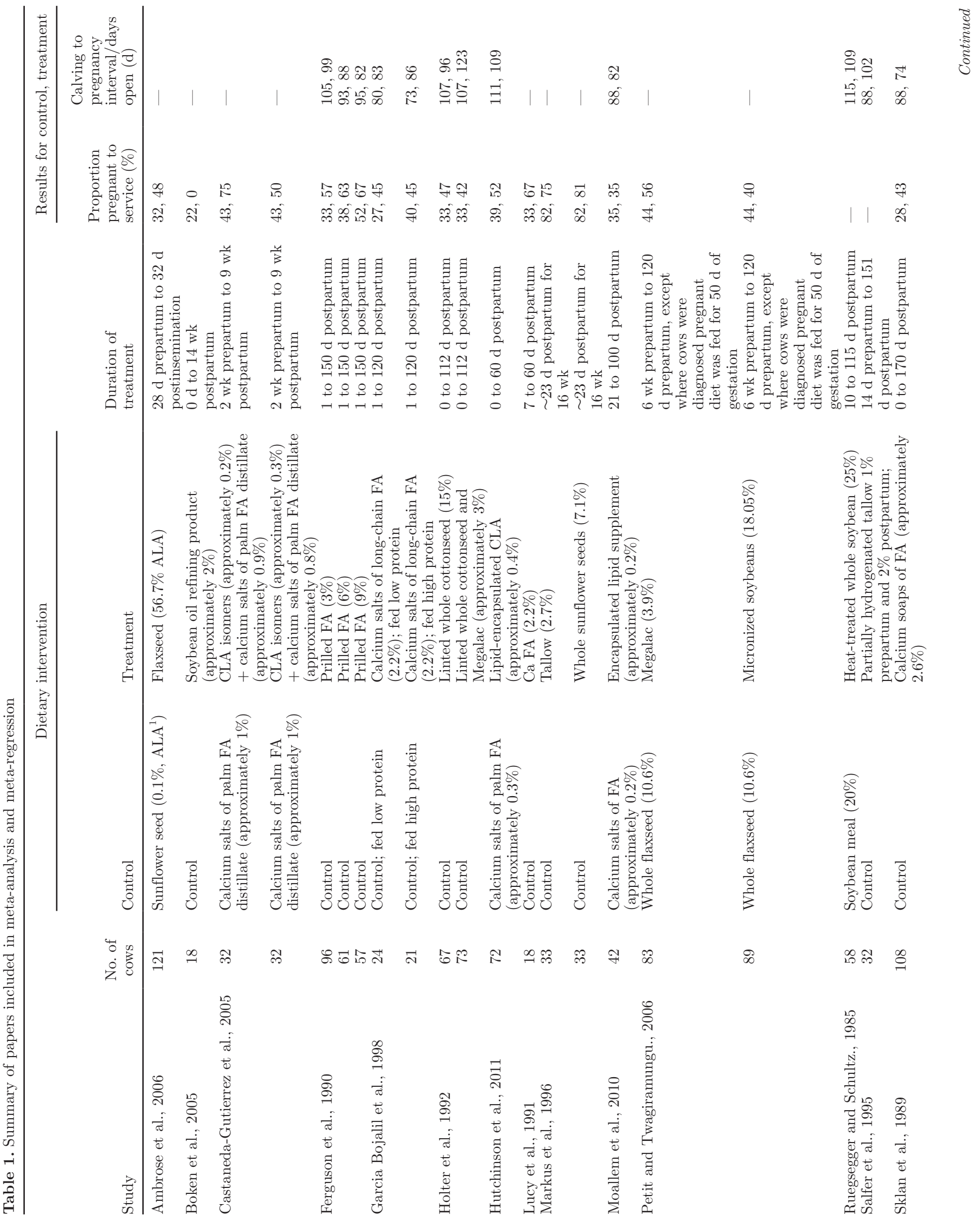




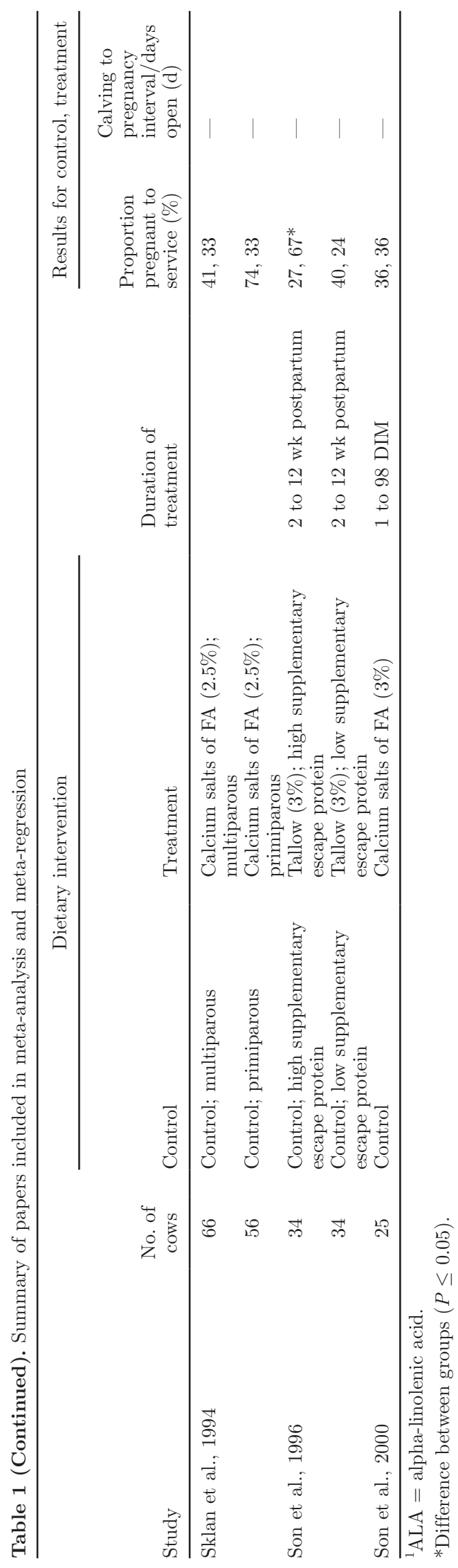

neity statistic divided by its degrees of freedom and describes the proportion of total variation in study estimates that is due to heterogeneity. Negative values of $I^{2}$ were assigned a value of zero, consequently the value $I^{2}$ lies between 0 and 100\%. An $I^{2}$ value greater than $50 \%$ indicates moderate heterogeneity (Higgins et al., 2003).

\section{Publication Bias}

We investigated the presence of publication bias using funnel plots, which are a scatter plot of the intervention effect estimates from individual studies plotted against study precision. The name funnel plot arises because precision of the estimated intervention effect increases as the size and precision of a study increases. Effect estimates from small studies will scatter more widely at the bottom of the graph and the spread narrows for larger studies. In the absence of bias, the plot should approximately resemble a symmetrical (inverted) funnel. If bias is present, for example because smaller studies without statistically significant effects remain unpublished, this will lead to an asymmetrical appearance of the funnel plot and a gap will be evident in a bottom corner of the graph (Duval and Tweedie, 2000). In this situation, the effect calculated in a meta-analysis will tend to overestimate the intervention effect.

\section{Mean Differences}

A weighted mean by group was calculated for dietary variables to identify differences between treatment and control groups that may possibly cause confounding. Using the values calculated by modeling in CPM-Dairy, the difference between treatment and control in each comparison was averaged across each fat type. A positive value indicates that the treatment group provides a greater value than the control group. Other fats were not explored because all comparisons in this group were from the same study. Lean et al. (2012) noted that in nutritional trials with an addition to the diet, inevitably a part of the diet is replaced. This may unintentionally add or reduce other nutritive components other than the variable of interest (e.g., a change in protein content) that could affect the outcome being measured. By examining these differences, potential sources of confounding can be identified.

\section{Meta-Regression}

Meta-regression analyses were used to explore sources of heterogeneity of response arising from diet for reproductive outcomes, using the individual $R R$ for each trial as the outcome and the associated standard 
error as the measure of variance. The differences between treatment and control groups for each variable were calculated and a random effects meta-regression analysis (Higgins and Thompson, 2002) was used to screen individual variables using a $P$-value of $\leq 0.20$. A bivariate model, including the effect of fat group, was conducted to assess dietary factors that influenced the proportion pregnant. All variables with $P$-value of $\leq 0.20$ in the bivariate meta-regression were further tested in a mixed model, including fat group, using a forward stepping meta-regression with explanatory variables with the lowest $P$-value entering the model first. Minerals were explored separately to other factors. Model fit during development of the final model was evaluated using $I^{2}, \tau^{2}$, and $\mathrm{R}^{2}$, where $I^{2}$ describes the percentage of total variation across studies that is due to heterogeneity (Higgins et al., 2003), $\tau^{2}$ is the variance of the standard deviation of the distribution of true effects across studies (Borenstein et al., 2011), and $\mathrm{R}^{2}$ is the ratio of explained variance to total variance, or the proportion of variance explained by that covariate (Borenstein et al., 2011). The assessment of model fit using $I^{2}, \tau^{2}$, and $\mathrm{R}^{2}$ was conducted according to methods described by Harbord and Higgins (2008). Due to the low number of trials identified for calving to pregnancy interval, a multivariate analysis was not conducted.

\section{RESULTS}

\section{Literature Review and Assessment}

The detailed systematic review identified more than 5,000 papers. All papers were critically reviewed against the selection criteria. Some studies contained a single comparison, whereas others reported 2 or more comparisons, which were assessed separately. Where a reason for exclusion could be clearly identified in the title of a paper, the study was excluded during the screening phase. Such exclusions included papers not in English, studies that used Bos indicus or crossbred cows or primiparous nonlactating heifers, studies unrelated to cattle or fats, and reviews. Of the papers that remained for eligibility $(\mathrm{n}=67)$, the main reasons studies were excluded from the meta-analysis were that they were not randomized controlled trials (i.e., were reviews, case studies, Latin-square, or crossover designs; 6 papers); included changes in nutritional intervention during the feeding period that could not be adequately quantified (30 papers); or reproductive variables measured were not those specified for inclusion (e.g., ovulation or reproductive hormone concentrations) or unit of interest was the oocyte or conceptus (14 papers).
Many of the studies excluded after assessment for eligibility examined valid interventions but contained a lack of detail about the diet or feed intake was not accurately measured (e.g., pasture, ad libitum, or group feeding), making the diets unsuitable for extraction. These interventions are still valid, although not able to be included in the analysis, and are detailed in Table 2 .

After assessment, 17 studies containing 26 comparisons were found suitable for inclusion in the metaanalysis. A range of different fat sources were identified for this analysis and papers were classified by fat type: oilseeds $(\mathrm{n}=6)$, CSFA $(\mathrm{n}=9)$, tallow $(\mathrm{n}=4)$, CLA ( $\mathrm{n}$ $=4)$, and other $(\mathrm{n}=3)$. The other group was composed solely of comparisons of prilled FA obtained from a single paper. Consequently, the ability to draw conclusions from this group is limited. However, these data have been included in the overall pooled estimates. A summary of these comparisons is available in Table 1.

\section{Mean Differences}

Mean differences between the nutritional composition of control and treatment diets are displayed by fat type in Table 3. Variation is present between treatments, but many of the differences are small. The difference in $\mathrm{ME}$ intake between treatment and control groups varies from $-4.06 \mathrm{MJ} / \mathrm{d}$ for the tallow treatment versus control to $0.3 \mathrm{MJ} / \mathrm{d}$ for CLA versus control. The CLA studies were the only group with a lower average $\mathrm{ME}$ balance in the treatment group. The greatest differences in MP balance between treatment and control groups were the diets including tallow $(-146.87 \mathrm{~g})$, which were lower than those of oilseed-based treatments $(-18.41$ g).

The difference in palmitic acid (C16:0) intake between control and treatment varied between fat types. The control diets for CLA based interventions provided, on average, a palmitic acid intake $11.47 \mathrm{~g}$ lower than treatment diets, and the CSFA treatment diets provided an average of $218.34 \mathrm{~g}$ more palmitic acid than controls. This intake difference was reflected in daily duodenal flux (-10.11 vs. $212.49 \mathrm{~g}$ for CLA and CSFA, respectively). Similar patterns were observed in the intake of oleic acid (C18:1cis) where the difference between control and treatment was very different for the CLA group (4.09 g more), whereas the tallow or CSFA treatments provided an intake of 189.25 and $132.54 \mathrm{~g}$ less, respectively. The differences between the control and treated cows for duodenal availability of $\mathrm{C} 18: 1$ cis were estimated to be $-6.43,42.21$, and $95.94 \mathrm{~g}$ for CLA, tallow, and CSFA, respectively. Differences in linoleic acid (C18:2) and linolenic acid (C18:3) intake were also noted between fat types (Table 3 ). 
FATS IMPROVE FERTILITY: A META-ANALYSIS

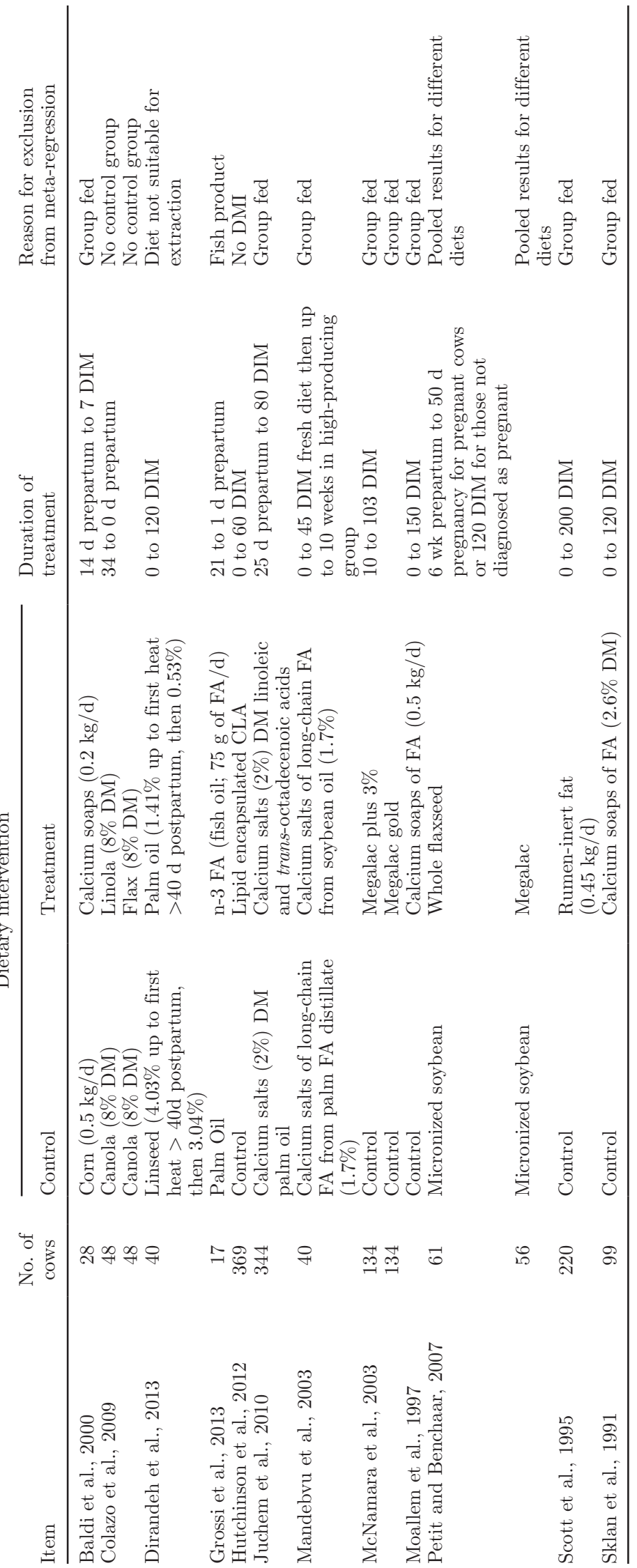




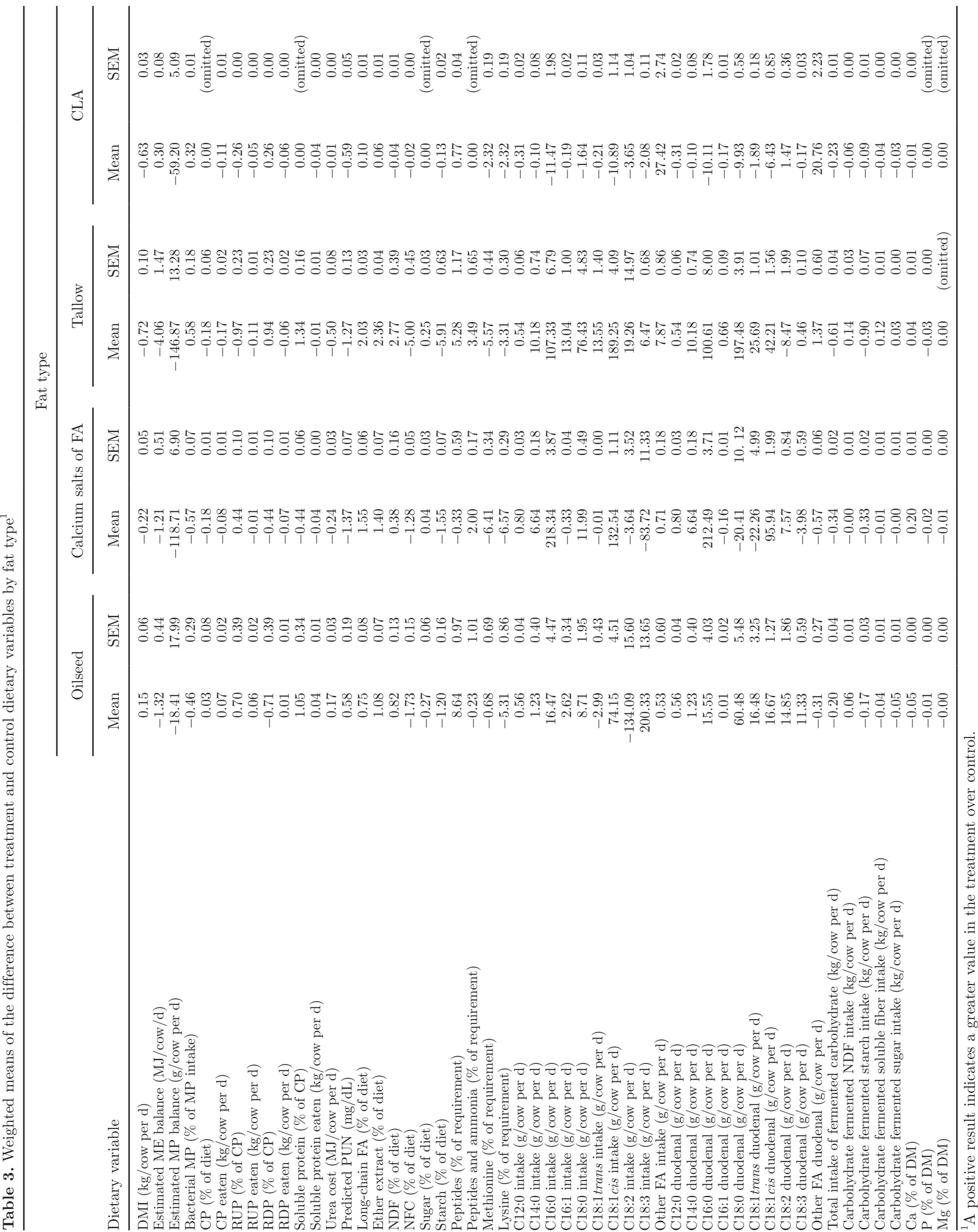




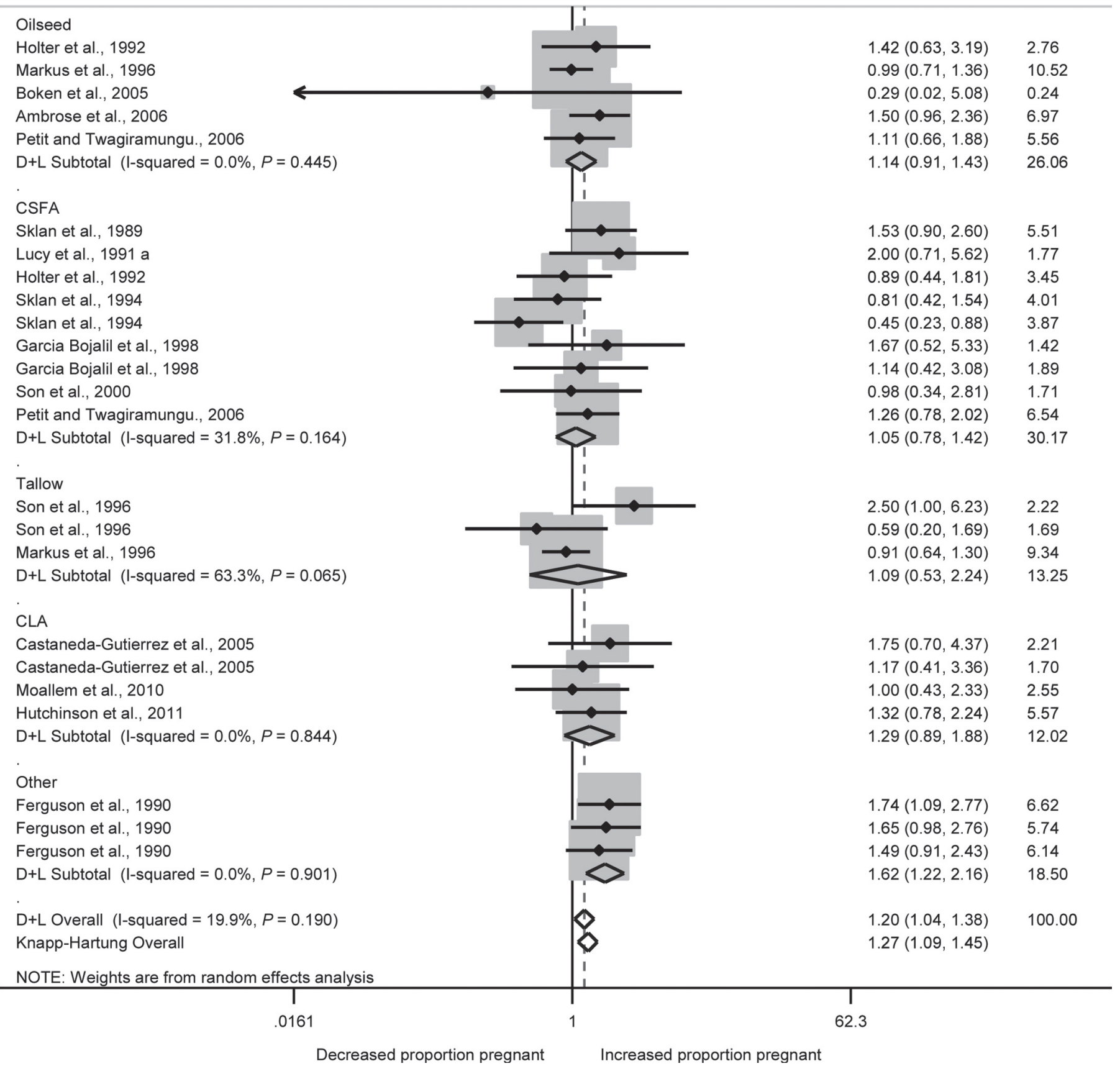

Figure 1. A forest plot of the studies that examined the relative risk of pregnancy to service (95\% CI) for dietary fat interventions. Studies were grouped by fat type, with a pooled estimate calculated for each group. An overall pooled estimate was made of the SMD, in this case relative risk (RR), using a random effects model using the DerSimonian and Laird (D+L) method (DerSimonian and Laird, 1986) and Knapp Hartung prediction (IntHout et al., 2014). The weights that each study contributed are in the right-hand column and are indicated by the size of the box. The larger the box, the greater the study contribution to the overall estimate. The solid vertical gray line represents a mean difference of zero or no effect. Points to the left of the line represent a reduction in risk of pregnancy to service, whereas points to the right of the line indicate an increase. The upper and lower limit of the line connected to the square represents the upper and lower $95 \%$ confidence interval for the effect size. Where the interval crosses 1, shown by whiskers crossing the solid vertical line, the change is insignificant. The overall pooled effects size and $95 \%$ confidence interval is indicated by the diamond at the bottom. This effect was moderately homogeneous as indicated by the $I^{2}$ of $25.7 \%$. D $+\mathrm{L}=$ DerSimonian and Laird. 
Table 4. Effects of feeding fats on reproduction, milk yield and composition, and BW: meta-analysis outputs using DeSimonian and Laird random effects model unless specified ${ }^{1}$

\begin{tabular}{|c|c|c|c|}
\hline Item & RR or SMD $(95 \% \mathrm{CI})$ & $I^{2}$ & $P$-value \\
\hline \multicolumn{4}{|c|}{ Proportion pregnant to service ${ }^{2}$} \\
\hline \multirow[t]{2}{*}{ Overall } & $1.20(1.04$ to 1.38$)$ & 19.9 & 0.19 \\
\hline & $\begin{array}{c}1.27 \text { (1.09 to1.45) } \\
\text { (Knapp-Hartung) }\end{array}$ & & \\
\hline Oilseed & $1.14(0.91$ to 1.43$)$ & 0.0 & 0.51 \\
\hline CSFA & $1.05(0.78$ to 1.42$)$ & 31.8 & 0.16 \\
\hline Tallow & $1.09(0.53$ to 2.24$)$ & 63.3 & 0.07 \\
\hline CLA & $1.29(0.89$ to 1.88$)$ & 0.0 & 0.84 \\
\hline \multicolumn{4}{|c|}{ Calving to pregnancy interval } \\
\hline Overall & $-0.16(-0.33$ to 0.00$)$ & 0.0 & 0.82 \\
\hline Oilseed & - & - & - \\
\hline CSFA & $-0.04(-0.28$ to 0.36$)$ & 0.0 & 0.46 \\
\hline Tallow & - & - & - \\
\hline CLA & $-0.32(-0.65$ to 0.01$)$ & 0.0 & 0.88 \\
\hline \multicolumn{4}{|c|}{ Milk yield } \\
\hline Overall & $0.33(-0.1$ to 0.67$)$ & 88.3 & 0.01 \\
\hline Oilseed & $-0.10(-0.97$ to 0.77$)$ & 92.7 & 0.01 \\
\hline CSFA & $0.73(0.00$ to 1.47$)$ & 92.1 & 0.01 \\
\hline Tallow & $0.21(-0.18$ to 0.60$)$ & 0.00 & 0.90 \\
\hline CLA & $0.52(-0.35$ to 1.39$)$ & 86.5 & 0.01 \\
\hline \multicolumn{4}{|c|}{ Protein \% } \\
\hline Overall & $-0.14(-0.38$ to 010$)$ & 74.3 & 0.01 \\
\hline Oilseed & $0.27(-0.05$ to 0.59$)$ & 41.6 & 0.16 \\
\hline CSFA & $-0.26(-0.61$ to 0.09$)$ & 58.9 & 0.02 \\
\hline Tallow & $-0.25(-0.65$ to 0.14$)$ & 0.00 & 0.65 \\
\hline CLA & $-0.45(-0.87$ to -0.03$)$ & 46.2 & 0.13 \\
\hline \multicolumn{4}{|c|}{ Protein yield } \\
\hline Overall & $0.34(-0.07$ to 0.75$)$ & 84.1 & 0.01 \\
\hline Oilseed & $0.18(-0.08$ to 0.44$)$ & 0.0 & 0.79 \\
\hline CSFA & $0.78(-0.25$ to 1.82$)$ & 92.5 & 0.01 \\
\hline Tallow & - & - & - \\
\hline CLA & $-0.11(-0.41$ to 0.19$)$ & 0.0 & 0.87 \\
\hline \multicolumn{4}{|l|}{ Fat yield } \\
\hline Overall & $0.04(-0.39$ to 0.47$)$ & 87.4 & 0.01 \\
\hline Oilseed & $0.29(0.03$ to 0.55$)$ & 0.0 & 0.57 \\
\hline CSFA & $0.64(0.05$ to 1.23$)$ & 85.1 & 0.01 \\
\hline Tallow & - & - & - \\
\hline CLA & $-1.00(-1.55$ to -0.44$)$ & 65.1 & 0.04 \\
\hline \multicolumn{4}{|l|}{ Fat $\%$} \\
\hline Overall & $-0.03(-0.32$ to 0.26$)$ & 84.3 & 0.01 \\
\hline Oilseed & $0.47(-0.01$ to 0.95$)$ & 76.9 & 0.01 \\
\hline CSFA & $0.19(-0.08$ to 0.46$)$ & 47.0 & 0.07 \\
\hline Tallow & $0.02(-0.68$ to 0.72$)$ & 67.3 & 0.05 \\
\hline CLA & $-1.39(-2.04$ to -0.74$)$ & 71.6 & 0.01 \\
\hline \multicolumn{4}{|l|}{$\mathrm{BW}$} \\
\hline Overall & $-0.15(-0.69$ to 0.40$)$ & 90.1 & 0.01 \\
\hline Oilseed & $-0.18(-0.71$ to 0.35$)$ & 81.2 & 0.01 \\
\hline CSFA & $0.10(-0.43$ to 0.62$)$ & 64.7 & 0.06 \\
\hline Tallow & $1.25(-0.70$ to 3.19$)$ & 92.0 & 0.01 \\
\hline CLA & - & - & - \\
\hline
\end{tabular}

${ }^{1} I^{2}$ describes the percentage of total variation across studies that is due to heterogeneity (Higgins et al., 2003). $\mathrm{CSFA}=$ calcium salts of FA.

${ }^{2}$ Relative risk (RR) is reported, whereas standardized mean difference (SMD) is reported for categories not signified with an asterisk. These are standardized units and do not correspond to normal metrics.

\section{Reproduction Outcomes}

The pooled estimates show that increasing dietary fat during the transition period increased the risk of pregnancy (proportion pregnant to service) by $27 \%$ when predicted using the method described by Knapp Hartung (95\% CI 1.09 to 1.45; Knapp and Hartung,
2003; Figure 1, Table 4). All groups tended to show a positive effect, but individually none (excluding other fats) showed an individually significant benefit. Only 2 comparisons showed individual significance in increased risk of pregnancy to service (Son et al., 1996, 2000). The RR for Boken et al. (2005) was individually negative $(\mathrm{RR}=0.29)$; however, as indicated by the small 


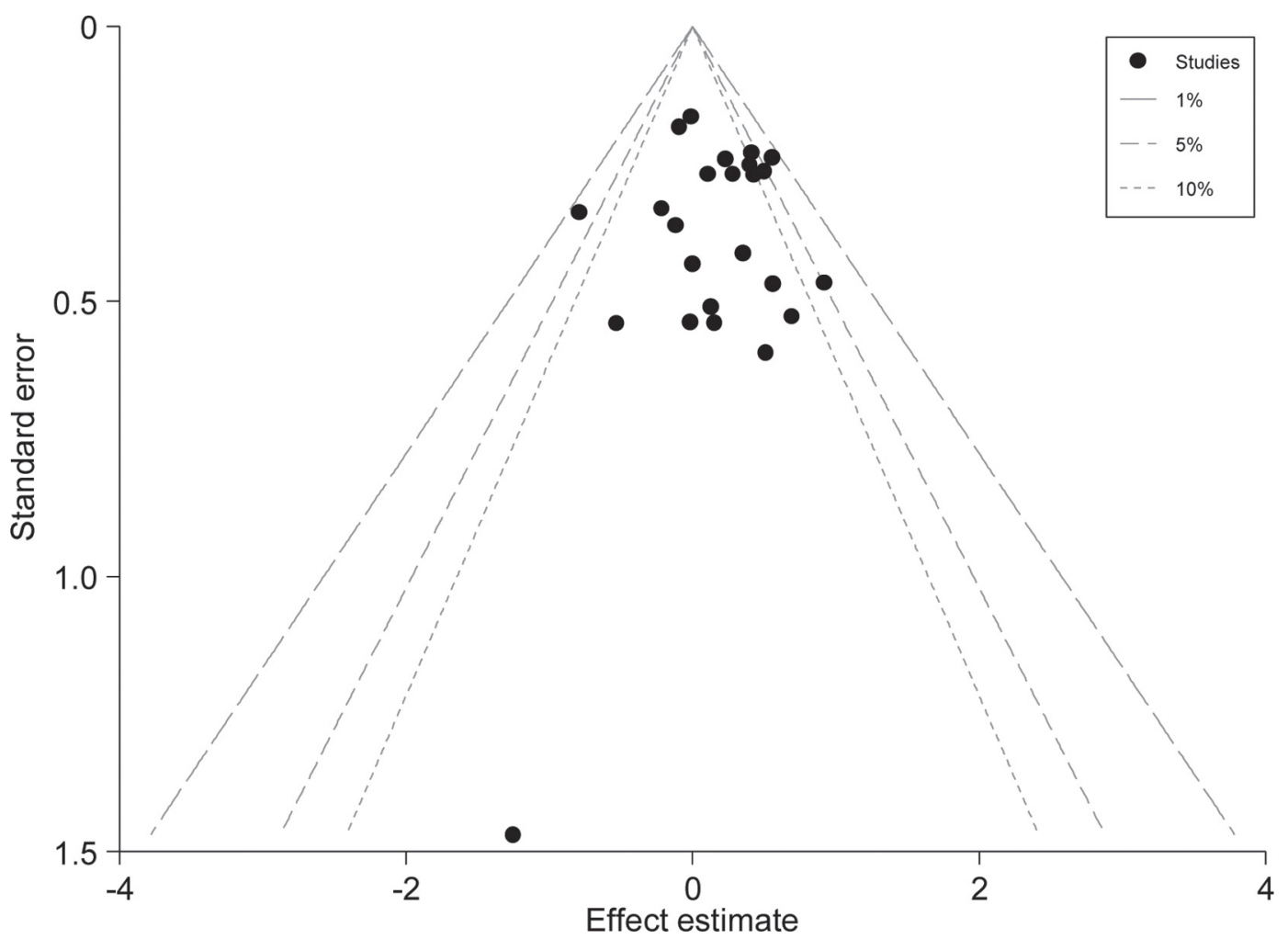

Figure 2. Contour-enhanced funnel plots for relative risk of pregnancy at first service for lactating dairy cows treated with different fats. Levels of significance for studies $(\bullet)$ within the gray broken lines are $0.01,0.05$, and 0.10 .

gray square in Figure 1, the weighting was small, reflecting the low number of cows in the trial (control $n$ $=9$, treatment $\mathrm{n}=6)$. Overall, the level of consistency among trials was moderately high $\left(I^{2}=19.9 \%\right)$ and the funnel plot was symmetrical (Figure 2), suggesting little publication bias. Investigation of the papers not suitable for meta-regression showed no notable change in effect size or direction of reproductive measures when included with other measures. These were not reported in the final meta-analysis, as their value to contribute was negated by considerable variability or confounding of the experimental design; a switching from one fat to another; feeding unsuitable fats (e.g., singular fats or fish oil); or unsuitable outcome variables.

The results of the bivariate meta-regression used to explore sources of heterogeneity of response arising from diet with the inclusion of fat groups are provided in Table 5. The proportion of cows pregnant increased with increasing intake of fermentable NDF and soluble fiber $(\mathrm{kg} / \mathrm{d})$ when assessed using a bivariate model accounting for fat group $(P=0.035$ and 0.015 , respectively). The estimated energetic cost of urea synthesis $(\mathrm{MJ} / \mathrm{d} ; P=0.022)$ was also positively associated with fertility. Increased actual milk yield $(\mathrm{kg} / \mathrm{d})$ for the treatment group decreased the proportion pregnant $(P=$
0.036). These relationships were all significant and had the same point direction in univariate models. These factors, and those with $P<0.2$ in the bivariate model [MP balance (g/d), NDF (\%), starch (\%), lysine (\% of requirement), C16:1 duodenal (g/d), fermentable sugar intake $(\mathrm{g} / \mathrm{d})$, and actual milk fat (\%; Table 5)] were assessed for inclusion in a multivariate model. However, no regression that combined more than 2 covariables with the effect of fat group resulted in significant covariables, apart from the fat group.

Most studies indicated that increasing dietary fat during the transition period numerically decreased calving to pregnancy interval, but none were individually significant (Figure 3). Only 10 comparisons provided adequate data to be included in this meta-analysis, and because only one comparison was available for oilseeds, this reduces considerably the inference range for this group. Of the remaining groups, CLA had the greatest effect $(\mathrm{SMD}=-0.41)$, although this was not significant. Overall, a high level of consistency of response among trials $\left(I^{2}=0.0 \%\right)$ was observed, but some potential for publication bias is present in these data as the funnel plot is not symmetrical (Figure 4). The asymmetry may, however, reflect the limited number of studies. Only oleic acid (C18:1 cis) intake and availability at 
Table 5. Bivariate meta-regression results controlling for the effect of fat group, for the effects of differences between treatment and control groups in dietary inputs on risk of proportion pregnant to service using Knapp Hartung (2003) methods

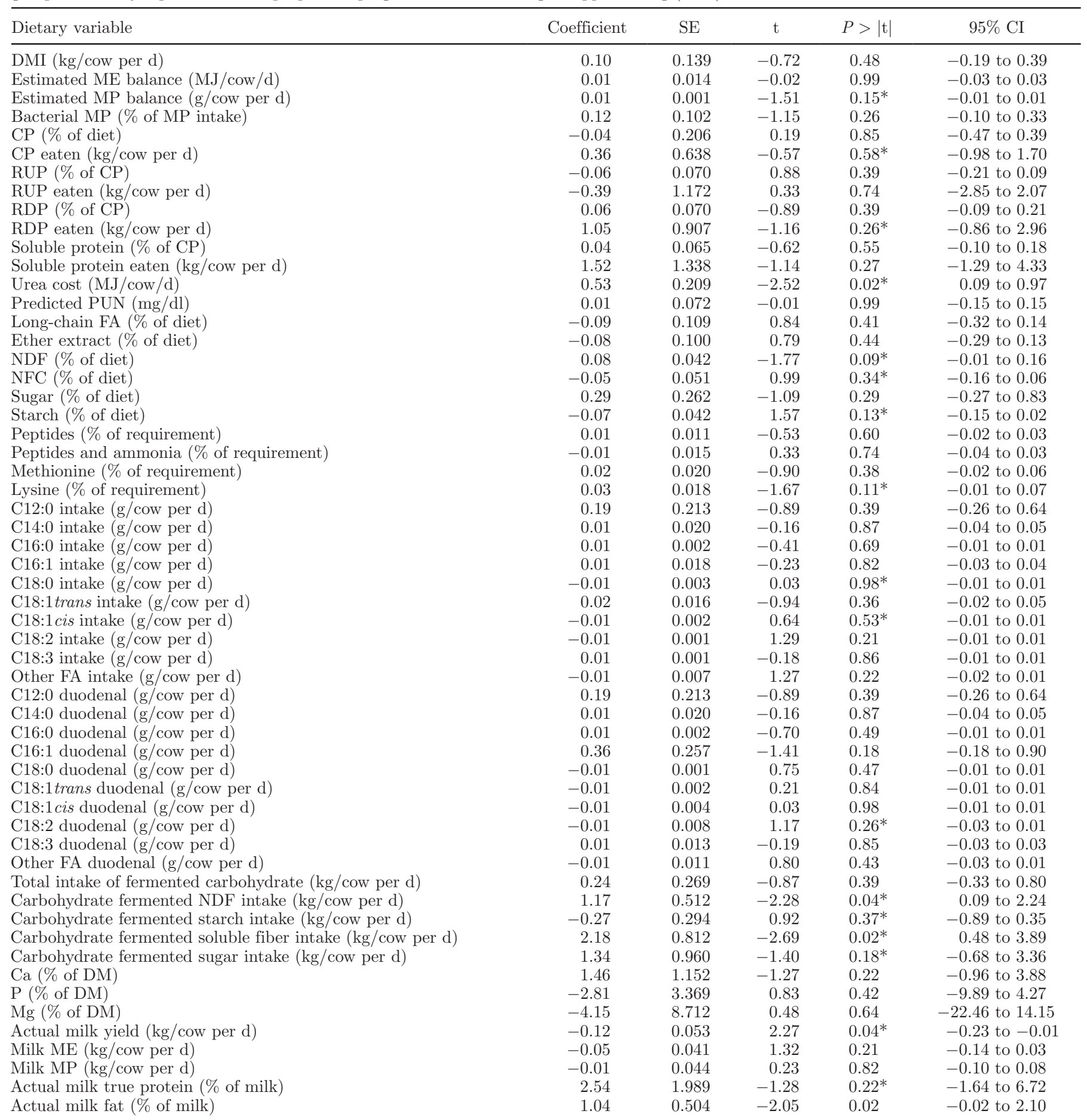

*Significant effects $(P<0.2)$ in the univariate meta-regression model are indicated by an asterisk. The effects $P<0.2$ in the bivariate model were evaluated for fit in a mixed model meta-regression.

the duodenum was associated with reduced calving to pregnancy interval, with a $P$-value $<0.2$. Therefore, no dietary measures were significantly associated with the calving to pregnancy interval (Table 6).

\section{Production Outcomes and Body Weight}

Overall, milk yield tended to increase with feeding fats during the transition period (pooled $\mathrm{SMD}=0.33$, 


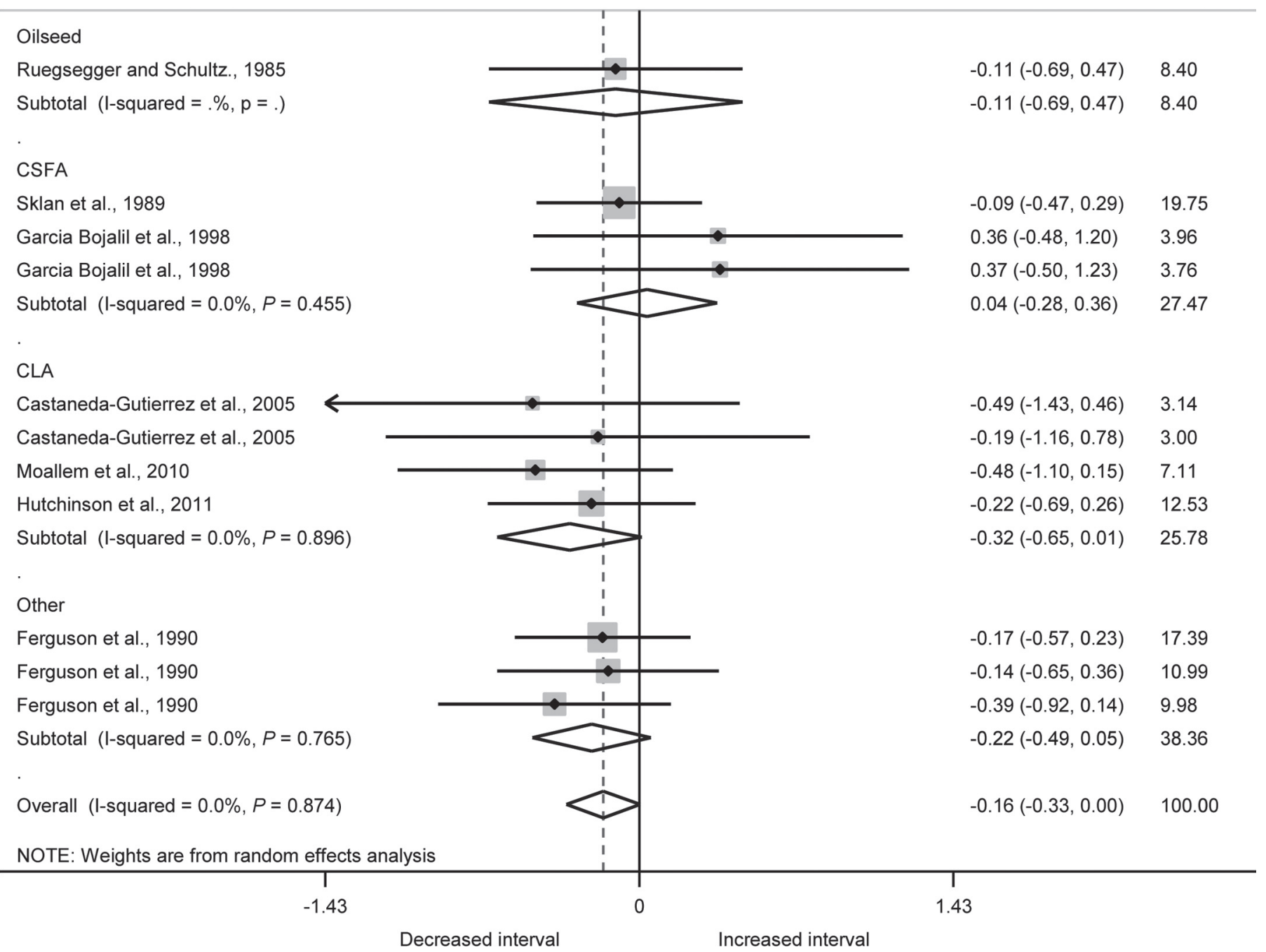

Figure 3. A forest plot of the effect size or standardized mean difference (SMD; standardized using the z-statistic) and 95\% confidence interval for trials comparing the calving to pregnancy interval of cows supplemented with fats during the transition and early lactation period. Estimates were made of the SMD using a random effects method (DerSimonian and Laird, 1986). The weights that each study contributed are in the right hand column and are indicated by the size of the box. The larger the box, the greater the study contribution to the overall estimate. The solid vertical gray line represents a mean difference of zero or no effect. Points to the left of the line represent a reduction in days to pregnancy, whereas points to the right of the line indicate an increase. The upper and lower limit of the line connected to the square represents the upper and lower $95 \%$ confidence interval for the effect size. The overall pooled effects size and $95 \%$ confidence interval is indicated by the diamonds at the bottom of each fat group. This effect was homogeneous as indicated by the $I^{2}$ of $0 \%$. An $I^{2}$ value for oilseeds is not available because this measure cannot be calculated for a single study, but this has been included in the overall pooled estimate.

$95 \% \mathrm{CI}=-0.01$ to 0.67 ; Figure 5). Meta-analysis results for production variables and BW are outlined in Table 4. Pooled estimates showed that feeding fats tended to have little effect on milk fat \% (SMD $=-0.03,95 \%$ CI $=-0.32$ to 0.26 ), except where CLA were fed and a significant decrease was observed $(\mathrm{SMD}=-1.39,95 \% \mathrm{CI}$ $=-2.04$ to -0.74$)$. Similarly, milk fat yield increased with oilseed and CSFA feeding $(\mathrm{SMD}=0.29,95 \% \mathrm{CI}=$ 0.03 to 0.55 , and $\mathrm{SMD}=0.64,95 \% \mathrm{CI}=0.05$ to 1.23 , respectively), but decreased when CLA were fed (SMD $=-1.00,95 \% \mathrm{CI}=-1.55$ to -0.44$)$. No tallow studies reported this variable. The difference in fat yield among groups for the overall pooled estimate was neutral $(\mathrm{SMD}=0.04,95 \% \mathrm{CI}-0.39$ to 0.47$)$. Feeding fats during transition tended to decrease milk protein percentage overall. Feeding CLA significantly reduced the percentage of protein in milk $(\mathrm{SMD}=-0.45,95 \% \mathrm{CI}$ -0.87 to -0.03$)$. The CSFA and tallow groups tended 


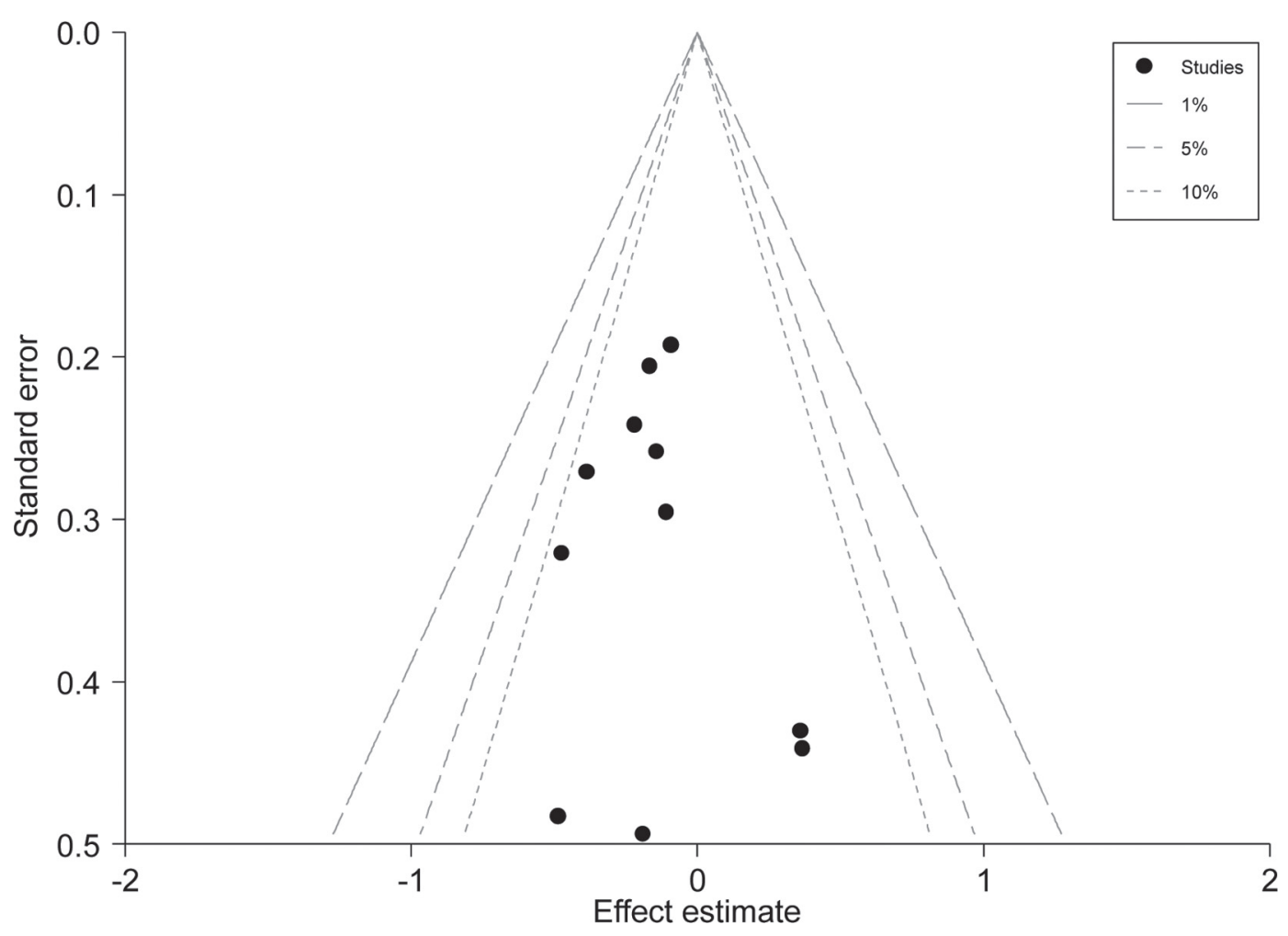

Figure 4. Contour-enhanced funnel plots for interval from calving to pregnancy for lactating dairy cows treated with different fats. Levels of significance for studies $(\bullet)$ within the gray broken lines are $0.01,0.05$, and 0.10 .

to decrease milk protein percentage; however, oilseeds tended to increase protein percentage. Overall, feeding fats tended to increase protein yield; however, this was not statistically significant $(\mathrm{SMD}=0.34,95 \% \mathrm{CI}-0.07$ to 0.75$)$. For all milk yield and composition variables, a high level of heterogeneity was observed among studies $\left(I^{2}=>80 \%\right)$ and funnel plots were asymmetrical, suggesting a potential for publication bias.

Feeding fats had no effect on BW (SMD $=-0.15$, $95 \%$, CI -0.69 to 0.40 ). Of these groups, tallow and CLA could not be explored individually because all comparisons within each group were from a single paper. Again, heterogeneity was high $\left(I^{2}=90.1 \%\right)$.

\section{DISCUSSION}

Despite more than 5,000 papers being initially identified in a systematic literature search on this topic, only 17 of these, providing 26 comparisons, were suitable for inclusion, a lower number than had been expected. The limited number of studies available for the current analyses highlights a need for more controlled studies to be conducted, containing sufficient information on exposure variables, in this case diet, examining reproductive outcomes such as pregnancy risk and interval to pregnancy.
One of the strengths of meta-analysis is that similar metrics, such as those used to measure proportion of cows pregnant to service, and interval to pregnancy, can be pooled using effect size measures such as those used in this study. There was also substantial variability in the fat content and type in control diets, a finding that is consistent with a meta-analysis by Rabiee et al. (2012) that explored the effects of fat nutrition on milk yield and composition. Meta-analysis and metaregression methods allow these sources of variation to be explored as a single data set and can help overcome these limitations by evaluating differences in treatment amounts of fat or differences in diet structure resulting from fat inclusion.

Fat feeding during transition has a variable effect on reproductive performance of lactating dairy cows with studies reporting mixed results (Grummer and Carroll, 1991). The feeding of fats before and immediately after calving has the potential to reduce DMI, particularly in heifers, but many studies are now available where beneficial effects of dietary fat have been observed on production and reproduction (Doepel et al., 2002; McNamara et al., 2003; Petit and Benchaar, 2007). McNamara et al. (2003) found that feeding fats increased first service pregnancy, but did not change overall percentage of cows pregnant. In the current study, the overall effects 
Table 6. Meta-regression results: intervals from calving to pregnancy

\begin{tabular}{|c|c|c|c|c|c|}
\hline Dietary variable & Coefficient & SE & $\mathrm{t}$ & $P>|\mathrm{t}|$ & $95 \% \mathrm{CI}$ \\
\hline Estimated ME balance (MJ/cow/d) & 0.01 & 0.029 & -0.02 & 0.98 & -0.06 to 0.07 \\
\hline Estimated MP balance (g/cow per d) & 0.01 & 0.001 & -0.02 & 0.98 & -0.01 to 0.01 \\
\hline $\mathrm{CP}(\%$ of diet) & -0.06 & 0.151 & 0.37 & 0.72 & -0.40 to 0.29 \\
\hline CP eaten $(\mathrm{kg} /$ cow per $\mathrm{d})$ & -0.08 & 0.600 & 0.14 & 0.89 & -1.44 to 1.27 \\
\hline RUP (\% of CP) & 0.01 & 0.023 & -0.17 & 0.87 & -0.05 to 0.06 \\
\hline RDP eaten $(\mathrm{kg} /$ cow per $\mathrm{d})$ & -0.27 & 0.849 & 0.32 & 0.75 & -2.20 to 1.65 \\
\hline Soluble protein (\% of $\mathrm{CP}$ ) & -0.01 & 0.038 & 0.08 & 0.94 & -0.09 to 0.08 \\
\hline Soluble protein eaten $(\mathrm{kg} /$ cow per d) & -0.20 & 1.193 & 0.17 & 0.87 & -2.90 to 2.50 \\
\hline Urea cost $(\mathrm{MJ} / \operatorname{cow} / \mathrm{d})$ & -0.44 & 0.545 & 0.81 & 0.44 & -1.67 to 0.79 \\
\hline Predicted PUN (mg/dL) & -0.02 & 0.045 & 0.37 & 0.72 & -0.12 to 0.09 \\
\hline Long-chain FA (\% of diet) & 0.09 & 0.103 & -0.90 & 0.39 & -0.14 to 0.33 \\
\hline Ether extract (\% of diet) & 0.12 & 0.114 & -1.08 & 0.31 & -0.13 to 0.38 \\
\hline Peptides and ammonia (\% of requirement) & -0.01 & 0.011 & 0.13 & 0.90 & -0.03 to 0.02 \\
\hline Methionine (\% of requirement) & -0.01 & 0.014 & 0.15 & 0.89 & -0.03 to 0.03 \\
\hline Lysine ( $\%$ of requirement) & -0.01 & 0.014 & 0.20 & 0.85 & -0.04 to 0.03 \\
\hline C12:0 intake ( $\mathrm{g} /$ cow per $\mathrm{d})$ & 0.19 & 0.197 & -0.99 & 0.35 & -0.25 to 0.64 \\
\hline $\mathrm{C} 14: 0$ intake $(\mathrm{g} /$ cow per $\mathrm{d})$ & 0.02 & 0.023 & -0.83 & 0.43 & -0.03 to 0.07 \\
\hline $\mathrm{C} 16: 0$ intake $(\mathrm{g} /$ cow per $\mathrm{d})$ & 0.01 & 0.001 & -0.72 & 0.49 & -0.01 to 0.01 \\
\hline $\mathrm{C} 16: 1$ intake $(\mathrm{g} /$ cow per $\mathrm{d})$ & 0.05 & 0.379 & -0.12 & 0.91 & -0.81 to 0.90 \\
\hline $\mathrm{C} 18: 0$ intake $(\mathrm{g} /$ cow per $\mathrm{d})$ & -0.01 & 0.001 & 0.36 & 0.73 & -0.01 to 0.01 \\
\hline C18:1trans intake (g/cow per $\mathrm{d})$ & -0.01 & 0.077 & 0.17 & 0.87 & -0.19 to 0.16 \\
\hline $\mathrm{C} 18: 1$ cis intake $(\mathrm{g} /$ cow per $\mathrm{d})$ & 0.01 & 0.002 & -1.46 & 0.18 & -0.01 to 0.01 \\
\hline $\mathrm{C} 18: 2$ intake $(\mathrm{g} /$ cow per $\mathrm{d})$ & 0.01 & 0.006 & -0.79 & 0.45 & -0.01 to 0.02 \\
\hline $\mathrm{C} 18: 3$ intake $(\mathrm{g} /$ cow per $\mathrm{d})$ & -0.002 & 0.022 & 0.08 & 0.94 & -0.05 to 0.05 \\
\hline Other FA intake ( $\mathrm{g} /$ cow per $\mathrm{d}$ ) & -0.00 & 0.005 & 0.75 & 0.47 & -0.01 to 0.01 \\
\hline C12:0 duodenal (g/cow per $\mathrm{d})$ & 0.19 & 0.197 & -0.99 & 0.35 & -0.25 to 0.64 \\
\hline Total intake of fermented carbohydrate $(\mathrm{kg} /$ cow per $\mathrm{d})$ & 0.06 & 0.445 & -0.13 & 0.90 & -0.95 to 1.06 \\
\hline Carbohydrate fermented NDF intake (kg/cow per d) & 0.181 & 1.393 & -0.13 & 0.90 & -2.98 to 3.33 \\
\hline Carbohydrate fermented starch intake (kg/cow per d) & 0.02 & 0.287 & -0.06 & 0.95 & -0.63 to 0.67 \\
\hline Carbohydrate fermented soluble fiber intake ( $\mathrm{kg} /$ cow per $\mathrm{d}$ ) & -0.41 & 1.356 & 0.30 & 0.77 & -0.47 to 2.66 \\
\hline Carbohydrate fermented sugar intake (kg/cow per d) & 0.18 & 0.974 & -0.18 & 0.86 & -0.03 to 2.38 \\
\hline $\mathrm{Ca}(\%$ of $\mathrm{DM})$ & 0.79 & 0.887 & -0.89 & 0.40 & -0.22 to 2.79 \\
\hline $\mathrm{P}(\%$ of $\mathrm{DM})$ & -8.09 & 9.564 & 0.85 & 0.42 & -9.73 to 13.54 \\
\hline $\mathrm{Mg}(\%$ of $\mathrm{DM})$ & -55.40 & 44.954 & 1.23 & 0.25 & -57.09 to 46.29 \\
\hline Actual milk yield ( $\mathrm{kg} /$ cow per $\mathrm{d}$ ) & 0.05 & 0.125 & -0.38 & 0.71 & -0.23 to 0.33 \\
\hline Milk ME (kg/cow per d) & 0.02 & 0.087 & -0.27 & 0.79 & -0.17 to 0.22 \\
\hline Milk MP (kg/cow per d) & 0.01 & 0.022 & -0.12 & 0.9 & -0.05 to 0.05 \\
\hline Actual milk true protein ( $\%$ of milk) & -0.19 & 1.731 & 0.11 & 0.92 & -4.10 to 3.73 \\
\hline Actual milk fat ( $\%$ of milk) & 0.27 & 0.335 & -0.81 & 0.44 & -0.49 to 1.03 \\
\hline
\end{tabular}

of fat feeding increased the proportion of cows pregnant to service and tended to reduce the interval from calving to pregnancy in treated cattle (Figures 1 and 2). When explored individually, the results show that each fat group tended to improve fertility; however, the limited number of studies available for analysis, and small size of many of these studies, prevented clear effects being identified. For the studies suitable for inclusion in this meta-analysis, reproductive responses were consistent with an $I^{2}$ of 19.9 and $0 \%$, indicating low heterogeneity for the proportion pregnant to service and interval from calving to pregnancy, respectively. Many of the 


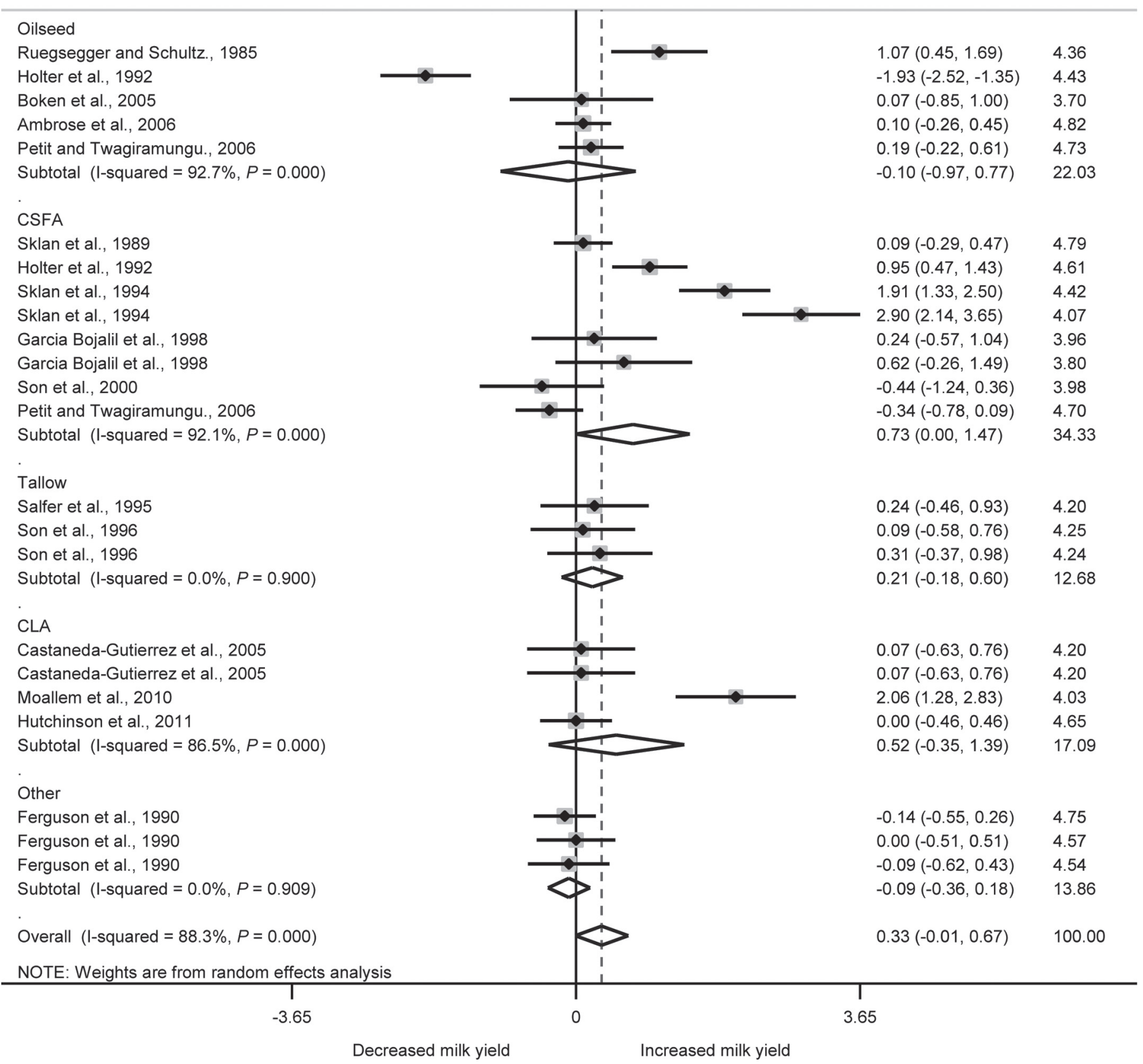

Figure 5. Forest plot of individual standardized mean difference (SMD), 95\% CI, and weights for trials comparing the milk yield of cows supplemented with fats during the transition and early lactation period. Estimates were made of the SMD using a random effects method (DerSimonian and Laird, 1986). The weights that each study contributed are in the right hand column and are indicated by the size of the box. The larger the box, the greater the study contribution to the overall estimate. The solid vertical gray line represents a mean difference of zero or no effect. Points to the left of the line represent a reduction in days to pregnancy, whereas points to the right of the line indicate an increase. The upper and lower limit of the line connected to the square represents the upper and lower $95 \%$ confidence interval for the effect size. The overall pooled effects size and $95 \%$ confidence interval is indicated by the diamonds at the bottom of each fat group. This effect was heterogeneous, as indicated by the $I^{2}$ of $88.3 \%$.

studies rejected for inclusion in the meta-analysis that still presented valid interventions (Table 2) also had positive responses to fats.
Increased milk yield $(\mathrm{kg} / \mathrm{d})$ of the treatment groups decreased the proportion pregnant in both univariate and multivariate meta-regression models $[P=0.02$ and 
$P=0.04$, respectively (unpublished and Table 5)]. Milk production demands of the freshly lactating cow exceed the capacity of DMI to deliver key nutrients including amino acids and energy precursors, ensuring most cows are in a state of negative nutrient balance in early lactation. Substantial energy deficits contribute to incidence of metabolic disease, decreased production (persistence and volume), and poor reproductive efficiency (Butler, 2000). Including fat can increase energy density of the diet, without increased dependence on rapidly fermentable carbohydrates, which, when fed at high levels, can compromise rumen and metabolic health. Inclusion of fats in the diet may also reduce liver triglyceride accumulation (Selberg et al., 2002) and concentrations of NEFA in blood (Doepel et al., 2002) immediately after calving and increase serum cholesterol concentrations (Rafalowski and Park, 1982; Carroll et al., 1990), a factor associated with better fertility. Westwood et al. (2000) found that higher concentrations of plasma cholesterol were associated with a shorter interval from calving to pregnancy, with greater probabilities of conception and successful pregnancy by d 150 of lactation. This finding is consistent with those of Kappel et al. (1984) and Ruegg et al. (1992), who found positive associations between cholesterol concentrations and fertility measures. Similarly, Moss (2001) found that low blood cholesterol concentrations at mating were strongly associated with pregnancy failure. Fatty acids are essential precursors for reproductive hormones, and Grummer and Carroll (1991) speculated that the presence of cholesterol-enriched lipoproteins could enhance progesterone production. This was supported by detection of increased levels of $\mathrm{PGF}_{2 \alpha}$ after feeding prilled long-chain FA (Carroll et al., 1990). Lipogenic precursors are also required for efficient milk production, and the optimal requirement was estimated to be 15 to $25 \%$ of energy supplied as lipogenic precursors, or about $8 \%$ long-chain FA in the diet (Kronfeld, 1976). Additionally, the tendency for pregnancy to be increased with higher milk fat percentages $(P=0.055)$ suggests that the ability of animals to spare fat for milk production is an indication of good metabolic status supporting reproduction.

Although no fat type individually increased fertility in this meta-analysis, feeding CLA has been an area of investigation previously showing positive results, although the number of high-quality studies is limited. De Veth et al. (2009) combined 5 studies and observed a marked improvement in median time to pregnancy (reduced from 151 to $117 \mathrm{~d}$ ) in cows fed a ruminally protected CLA compared with unsupplemented cows. Thatcher et al. (2006) also found positive effects of supplementation with ruminally protected CLA and palm FA on reproduction and health. von Soosten et al. (2012) identified a trend toward lower body mass mobilization in cattle fed protected CLA, when compared with a stearic-acid-based fat supplement, suggesting a protective effect of CLA supplementation on use of body reserves in early lactation, possibly through more efficient utilization of ME. The current meta-analysis did not show a significant effect of fat feeding on BW, but was not able to explore CLA feeding individually as only one of the papers that reported CLA responses provided details on BW.

Fats are also important sources of essential FA. Linoleic (C18:2) and linolenic FA (C18:3) are classified as essential FA and must be supplied in the diet (Mattos et al., 2000). Unsaturated FA [especially linoleic acid, linolenic acid, eicosapentaenoic acid (C20:5), and docosahexaenoic acid (C22:6)] may target reproductive tissues when supplied in a form absorbed in the lower gut (Thatcher et al., 2006). Lean and Rabiee (2006) estimated that availability of essential FA at the duodenum is approximately one-half that for cattle fed TMR based on maize and alfalfa silage compared with cows fed pasture-based diets. Linolenic acid (C18:3) predominates in forage lipids (Palmquist and Jenkins, 1980), and concentrations of linoleic acid (C18:2) are high in some pastures. This difference, combined with high digesta flow rates of lush pastures, may in part explain the differences in reproductive performance seen between pasture-based herds and those maintained in TMR systems, such as those seen in North America. Hutchinson et al. (2011) found a trend toward lower services per pregnancy, but little overall effect of supplementation, with feeding protected CLA on fertility of cows on pasture, a finding consistent with the suggestions of Lean and Rabiee (2006) that at least some of the difference in fertility of cows on pasture-based diets and those on TMR diets may reflect the CLA generated from pasture.

In this meta-analysis, the potentially confounding effects of diet formulation to include fats in the diet were controlled by using meta-regression. Differences were identified in intakes and duodenal concentration of FA among the different groups of fats fed (Table 3); however, these differences did not influence outcomes when evaluated by meta-regression. Increasing dietary intake of slower fermenting carbohydrates (NDF and soluble fiber) favored proportion pregnant, possibly because slower fermentation results in more stable rumen conditions and promotes microbial growth. Chalupa et al. (1986) found that including high levels of fat in the diet affected microbial metabolism, as indicated by a decrease in the ratio of acetate to propionate concentrations in the rumen. This response in acetate:propionate 
ratio varied with the type of fat used, as the depression was greater in response to oleic acids and animal tallows than CSFA and stearic acid. The positive association between the energetic cost of urea synthesis and pregnancy was unexpected, but may reflect a need for soluble protein intake to increase in high-fat diets to maintain microbial protein synthesis and highlights the multivariable responses to nutritional intervention.

Although milk yield was not significantly increased by feeding fats during the transition period, other meta-analyses that included a greater number of comparisons found significant increases (Rabiee et al., 2012; Boerman, 2014). These studies (Rabiee et al., 2012; Boerman, 2014) both found an overall milk yield response of $1.05 \mathrm{~kg} / \mathrm{cow}$ per d from fat feeding. A meta-analysis (Onetti and Grummer, 2004) found no significant change in milk yield when tallow of selected hydrolyzed FA were fed, whereas including CSFA in the diet increased yield. In the current study, CSFA interventions increased yield and milk fat yield, but did not affect milk composition because no differences were found in milk protein, but the study power was low compared with other meta-analyses.

More consistency was observed in reproductive responses to fats than for milk and milk components where marked differences in responses to different fats were observed. This greater variability is consistent with Rabiee et al. (2012), who included studies in which fat was fed any time during lactation, whereas this paper has a focus only on fats fed during transition. This distinction is important because evidence is increasing that nutrition during the transition period has a pivotal role on performance, especially reproduction in the following lactation (Thatcher et al., 2011).

\section{CONCLUSIONS}

Feeding fats has a positive effect on fertility and a tendency to increase production when fed during the transition period. Feeding fats during transition may be an essential component of an integrated response to the challenges of controlling tissue mobilization in early lactation and limiting the amount of fermentable carbohydrate fed. However, meta-regression of the difference in diets between treatment and control groups did not identify the reasons for these improvements in regard to the FA composition of the diet. The limited number of papers identified from the literature search and the positive results of this study support the need for further work exploring the effects of including fat in the diet of the transition cow on fertility and the development of guidelines to assist study design in this area of research.

\section{ACKNOWLEDGMENTS}

This research was supported by funding from Dairy Australia (Melbourne, Victoria) and SBScibus.

\section{REFERENCES}

Ambrose, D. J., J. P. Kastelic, R. Corbett, P. A. Pitney, H. V. Petit, J. A. Small, and P. Zalkovic. 2006. Lower pregnancy losses in lactating dairy cows fed a diet enriched in alpha-linolenic acid. J. Dairy Sci. 89:3066-3074.

Baldi, A., G. Savoini, L. Pinotti, E. Monfardini, F. Cheli, and V. Dell'Orto. 2000. Effects of vitamin $\mathrm{E}$ and different energy sources on vitamin E status, milk quality and reproduction in transition cows. J. Vet. Med. A Physiol. Pathol. Clin. Med. 47:599-608.

Bell, A. 1995. Regulation of organic nutrient metabolism during transition from late pregnancy to early lactation. J. Anim. Sci. 73:2804-2819.

Boerman, J. 2014. Feed intake and production responses of lactating dairy cows when commercially available fat supplements are included in diets: A meta-analysis. J. Dairy Sci. 97(E-Suppl. 1):319. (Abstr.).

Boken, S., C. Staples, L. Sollenberger, T. Jenkins, and W. Thatcher. 2005. Effect of grazing and fat supplementation on production and reproduction of Holstein cows. J. Dairy Sci. 88:4258-4272.

Borenstein, M., L. V. Hedges, J. P. Higgins, and H. R. Rothstein. 2011. Introduction to Meta-Analysis. John Wiley \& Sons, Hoboken, NJ.

Butler, W. 2000. Nutritional interactions with reproductive performance in dairy cattle. Anim. Reprod. Sci. 60-61:449-457.

Carroll, D., M. Jerred, R. Grummer, D. Combs, R. Pierson, and E. Hauser. 1990. Effects of fat supplementation and immature alfalfa to concentrate ratio on plasma progesterone, energy balance, and reproductive traits of dairy cattle. J. Dairy Sci. 73:2855-2863.

Castaneda-Gutierrez, E., T. Overton, W. Butler, and D. Bauman. 2005. Dietary supplements of two doses of calcium salts of conjugated linoleic acid during the transition period and early lactation. J. Dairy Sci. 88:1078-1089.

Chalupa, W., B. Vecchiarelli, A. Elser, D. Kronfeld, D. Sklan, and D. Palmquist. 1986. Ruminal fermentation in vivo as influenced by long-chain fatty acids. J. Dairy Sci. 69:1293-1301.

Colazo, M. G., A. Hayirli, L. Doepel, and D. J. Ambrose. 2009. Reproductive performance of dairy cows is influenced by prepartum feed restriction and dietary fatty acid source. J. Dairy Sci. 92:25622571.

de Veth, M., D. Bauman, W. Koch, G. Mann, A. Pfeiffer, and W. Butler. 2009. Efficacy of conjugated linoleic acid for improving reproduction: A multi-study analysis in early-lactation dairy cows. J. Dairy Sci. 92:2662-2669.

DeGaris, P., I. Lean, A. Rabiee, and C. Heuer. 2010a. Effects of increasing days of exposure to prepartum transition diets on reproduction and health in dairy cows. Aust. Vet. J. 88:84-92.

DeGaris, P., I. Lean, A. Rabiee, and M. Stevenson. 2010b. Effects of increasing days of exposure to prepartum diets on the concentration of certain blood metabolites in dairy cows. Aust. Vet. J. 88:137-145

DerSimonian, R., and N. Laird. 1986. Meta-analysis in clinical trials. Control. Clin. Trials 7:177-188.

Dirandeh, E., A. Towhidi, S. Zeinoaldini, M. Ganjkhanlou, Z. A. Pirsaraei, and A. Fouladi-Nashta. 2013. Effects of different polyunsaturated fatty acid supplementations during the postpartum periods of early lactating dairy cows on milk yield, metabolic responses, and reproductive performances. J. Anim. Sci. 91:713-721.

Doepel, L., H. Lapierre, and J. Kennelly. 2002. Peripartum performance and metabolism of dairy cows in response to prepartum energy and protein intake. J. Dairy Sci. 85:2315-2334.

Duval, S., and R. Tweedie. 2000. Trim and fill: A simple funnel-plotbased method of testing and adjusting for publication bias in meta-analysis. Biometrics 56:455-463. 
Ferguson, J., D. Sklan, W. Chalupa, and D. Kronfeld. 1990. Effects of hard fats on in vitro and in vivo rumen fermentation, milk production, and reproduction in dairy cows. J. Dairy Sci. 73:2864-2879.

Garcia-Bojalil, C., C. Staples, C. Risco, J. Savio, and W. Thatcher. 1998. Protein degradability and calcium salts of long-chain fatty acids in the diets of lactating dairy cows: Reproductive responses. J. Dairy Sci. 81:1385-1395.

Grossi, P., G. Bertoni, F. P. Cappelli, and E. Trevisi. 2013. Effects of the precalving administration of omega-3 fatty acids alone or in combination with acetylsalicylic acid in periparturient dairy cows. J. Anim. Sci. 91:2657-2666.

Grummer, R., and D. Carroll. 1991. Effects of dietary fat on metabolic disorders and reproductive performance of dairy cattle. J. Anim. Sci. 69:3838-3852.

Harbord, R. M., and J. Higgins. 2008. Meta-regression in Stata. Meta $8: 493-519$

Harris, R., M. Bradburn, J. Deeks, R. Harbord, D. Altman, and J. Sterne. 2008. Metan: Fixed- and random-effects meta-analysis. Stata J. 8:3-28.

Higgins, J., and S. G. Thompson. 2002. Quantifying heterogeneity in a meta-analysis. Stat. Med. 21:1539-1558.

Higgins, J., S. G. Thompson, J. J. Deeks, and D. G. Altman. 2003. Measuring inconsistency in meta-analyses. BMJ 327:557-560.

Holter, J., H. Hayes, W. Urban Jr., and A. Duthie. 1992. Energy balance and lactation response in Holstein cows supplemented with cottonseed with or without calcium soap. J. Dairy Sci. 75:14801494.

Hutchinson, I., M. J. de Veth, C. Stanton, R. J. Dewhurst, P. Lonergan, A. C. Evans, and S. T. Butler. 2011. Effects of lipid-encapsulated conjugated linoleic acid supplementation on milk production, bioenergetic status and indicators of reproductive performance in lactating dairy cows. J. Dairy Res. 78:308-317.

Hutchinson, I. A., A. Hennessy, R. J. Dewhurst, A. Evans, P. Lonergan, and S. T. Butler. 2012. The effect of strategic supplementation with trans-10, cis-12 conjugated linoleic acid on the milk production, estrous cycle characteristics, and reproductive performance of lactating dairy cattle. J. Dairy Sci. 95:2442-2451.

IntHout, J., J. P. Ioannidis, and G. F. Borm. 2014. The HartungKnapp-Sidik-Jonkman method for random effects meta-analysis is straightforward and considerably outperforms the standard DerSimonian-Laird method. BMC Med. Res. Methodol. 14:25-37.

Juchem, S. O., R. L. A. Cerri, M. Villasenor, K. N. Galvao, R. G. S. Bruno, H. M. Rutigliano, E. J. DePeters, F. T. Silvestre, W. W. Thatcher, and J. E. P. Santos. 2010. Supplementation with calcium salts of linoleic and trans-octadecenoic acids improves fertility of lactating dairy cows. Reprod. Domest. Anim. 45:55-62.

Kappel, L., R. Ingraham, E. Morgan, L. Zeringue, D. Wilson, and D. Babcock. 1984. Relationship between fertility and blood glucose and cholesterol concentrations in Holstein cows. Am. J. Vet. Res. 45:2607-2612.

Knapp, G., and J. Hartung. 2003. Improved tests for a random effects meta-regression with a single covariate. Stat. Med. 22:2693-2710.

Kronfeld, D. 1976. The potential importance of the proportions of glucogenic, lipogenic and aminogenic nutrients in regard to the health and productivity of dairy cows. Fortschritte in der Tierphysiologie und Tierernaehrung (Germany, FR) pp. 5-26.

Lean, I., and A. Rabiee. 2006. Quantitative metabolic and epidemiological approaches to fertility of the dairy cow. Pages 115-131 in Dairy Cattle Reproduction Council (DCRC) Proc., Denver, CO.

Lean, I., A. Rabiee, T. Duffield, and I. Dohoo. 2009. Invited review: Use of meta-analysis in animal health and reproduction: Methods and applications. J. Dairy Sci. 92:3545-3565.

Lean, I., C. Westwood, and M. Playford. 2008. Livestock disease threats associated with intensification of pastoral dairy farming. N. Z. Vet. J. 56:261-269.

Lean, I. J., P. Celi, H. Raadsma, J. McNamara, and A. R. Rabiee. 2012. Effects of dietary crude protein on fertility: Meta-analysis and meta-regression. Anim. Feed Sci. Technol. 171:31-42.

Lucy, M. C. 2001. Reproductive loss in high-producing dairy cattle: Where will it end? J. Dairy Sci. 84:1277-1293.
Lucy, M. C., C. Staples, F. Michel, W. Thatcher, and D. Bolt. 1991. Effect of feeding calcium soaps to early postpartum dairy cows on plasma prostaglandin $\mathrm{F}_{2 \alpha}$ luteinizing hormone, and follicular growth. J. Dairy Sci. 74:483-489.

Mandebvu, P., C. Ballard, C. Sniffen, M. Carter, H. Wolford, T. Sato, Y. Yabuuchi, E. Block, and D. Palmquist. 2003. Effect of feeding calcium salts of long-chain fatty acids, from palm fatty acid distillate or soybean oil, to high producing dairy cows on milk yield and composition, and on selected blood and reproductive parameters. Anim. Feed Sci. Technol. 108:25-41.

Markus, S., K. Wittenberg, J. Ingalls, and M. Undi. 1996. Production responses by early lactation cows to whole sunflower seed or tallow supplementation of a diet based on barley. J. Dairy Sci. $79: 1817-1825$

Mattos, R., C. R. Staples, and W. W. Thatcher. 2000. Effects of dietary fatty acids on reproduction in ruminants. Rev. Reprod. $5: 38-45$.

McNamara, S., T. Butler, D. Ryan, J. Mee, P. Dillon, F. O'Mara, S. Butler, D. Anglesey, M. Rath, and J. Murphy. 2003. Effect of offering rumen-protected fat supplements on fertility and performance in spring-calving Holstein-Friesian cows. Anim. Reprod. Sci. $79: 45-56$.

Moallem, U., M. Kaim, Y. Folman, and D. Sklan. 1997. Effect of calcium soaps of fatty acids and administration of somatotropin in early lactation on productive and reproductive performance of high producing dairy cows. J. Dairy Sci. 80:2127-2136.

Moallem, U., H. Lehrer, M. Zachut, L. Livshitz, and S. Yacoby 2010. Production performance and pattern of milk fat depression of high-yielding dairy cows supplemented with encapsulated conjugated linoleic acid. Animal 4:641-652.

Moss, N. 2001. The epidemiology of subfertility in Australian dairy cows. PhD Thesis. University of Sydney, NSW, Australia.

Onetti, S., and R. Grummer. 2004. Response of lactating cows to three supplemental fat sources as affected by forage in the diet and stage of lactation: A meta-analysis of literature. Anim. Feed Sci. Technol. 115:65-82.

Palmquist, D., and T. Jenkins. 1980. Fat in lactation rations . J. Dairy Sci. $63: 1-14$.

Petit, H., and C. Benchaar. 2007. Milk production, milk composition, blood composition, and conception rate of transition dairy cows fed different profiles of fatty acids. Can. J. Anim. Sci. 87:591-600.

Petit, H. V., and H. Twagiramungu. 2006. Conception rate and reproductive function of dairy cows fed different fat sources. Theriogenology 66:1316-1324.

Rabiee, A. R., K. Breinhild, W. Scott, H. M. Golder, E. Block, and I. J. Lean. 2012. Effect of fat additions to diets of dairy cattle on milk production and components: A meta-analysis and metaregression. J. Dairy Sci. 95:3225-3247.

Rafalowski, W., and C. Park. 1982. Whole sunflower seed as a fat supplement for lactating cows. J. Dairy Sci. 65:1484-1492.

Ruegg, P., W. Goodger, C. Holmberg, L. Weaver, and E. Huffman. 1992. Relation among body condition score, milk production, and serum urea nitrogen and cholesterol concentrations in high-producing Holstein dairy cows in early lactation. Am. J. Vet. Res. $53: 5-9$.

Ruegsegger, G., and L. Schultz. 1985. Response of high producing dairy cows in early lactation to the feeding of heat-treated whole soybeans. J. Dairy Sci. 68:3272-3279.

Salfer, J., J. Linn, D. Otterby, W. Hansen, and D. Johnson. 1995. Early lactation responses of Holstein cows fed a rumen-inert fat prepartum, postpartum, or both. J. Dairy Sci. 78:368-377.

Scott, T., R. Shaver, L. Zepeda, B. Yandell, and T. Smith. 1995. Effects of rumen-inert fat on lactation, reproduction, and health of high producing Holstein herds. J. Dairy Sci. 78:2435-2451.

Selberg, K., C. Staples, and L. Badinga. 2002. Production and metabolic responses to dietary conjugated linoleic acid (CLA) and trans-octadecenoic acid isomers in periparturient dairy cows. J. Dairy Sci. 85(Suppl. 1):19.

Sklan, D., E. Bogin, Y. Avidar, and S. Gur-Arie. 1989. Feeding calcium soaps of fatty acids to lactating cows: Effect on production, body condition and blood lipids. J. Dairy Res. 56:675-681. 
Sklan, D., M. Kaim, U. Moallem, and Y. Folman. 1994. Effect of dietary calcium soaps on milk yield, body weight, reproductive hormones, and fertility in first parity and older cows. J. Dairy Sci. $77: 1652-1660$

Sklan, D., U. Moallem, and Y. Folman. 1991. Effect of feeding calcium soaps of fatty acids on production and reproductive responses in high producing lactating cows. J. Dairy Sci. 74:510-517.

Son, J., R. Grant, and L. Larson. 1996. Effects of tallow and escape protein on lactational and reproductive performance of dairy cows. J. Dairy Sci. 79:822-830.

Son, J., L. Larson, and R. Grant. 2000. Effect of time of initiating dietary fat supplementation on performance and reproduction of early lactation dairy cows. Asian-australas. J. Anim. Sci. 13:182187.
Thatcher, W., T. Bilby, J. Bartolome, F. Silvestre, C. Staples, and J. Santos. 2006. Strategies for improving fertility in the modern dairy cow. Theriogenology 65:30-44.

Thatcher, W., J. E. Santos, and C. R. Staples. 2011. Dietary manipulations to improve embryonic survival in cattle. Theriogenology 76:1619-1631.

von Soosten, D., U. Meyer, M. Piechotta, G. Flachowsky, and S. Dänicke. 2012. Effect of conjugated linoleic acid supplementation on body composition, body fat mobilization, protein accretion, and energy utilization in early lactation dairy cows. J. Dairy Sci. 95:1222-1239.

Westwood, C., I. Lean, J. Garvin, and P. Wynn. 2000. Effects of genetic merit and varying dietary protein degradability on lactating dairy cows. J. Dairy Sci. 83:2926-2940. 